SPIE 6173-49

\title{
Design, fabrication, and testing of a SMA hybrid composite jet engine chevron
}

\author{
Travis L. Turner ${ }^{*}$, Randolph H. Cabell ${ }^{* *}$, Roberto J. Cano ${ }^{\dagger}$, and Gary A. Fleming ${ }^{\ddagger}$ \\ NASA Langley Research Center, Hampton, VA USA 23681-2199
}

\begin{abstract}
Control of jet noise continues to be an important research topic. Exhaust nozzle chevrons have been shown to reduce jet noise, but parametric effects are not well understood. Additionally, thrust loss due to chevrons at cruise suggests significant benefit from deployable chevrons. The focus of this study is development of an active chevron concept for the primary purpose of parametric studies for jet noise reduction in the laboratory and technology development to leverage for full scale systems. The active chevron concept employed in this work consists of a laminated composite structure with embedded shape memory alloy (SMA) actuators, termed a SMA hybrid composite (SMAHC). The actuators are embedded on one side of the middle surface such that thermal excitation generates a moment and deflects the structure. A brief description of the chevron design is given followed by details of the fabrication approach. Results from bench top tests are presented and correlated with numerical predictions from a model for such structures that was recently implemented in MSC.Nastran and ABAQUS. Excellent performance and agreement with predictions is demonstrated. Results from tests in a representative flow environment are also presented. Excellent performance is again achieved for both open- and closed-loop tests, the latter demonstrating control to a specified immersion into the flow. The actuation authority and immersion performance is shown to be relatively insensitive to nozzle pressure ratio (NPR). Very repeatable immersion control with modest power requirements is demonstrated.
\end{abstract}

Keywords: shape memory alloys, Nitinol, embedded actuators, jet engine chevrons, active chevrons, shape control, deflection control, jet noise control, flow effectors, flow control

\section{INTRODUCTION}

Reduction of jet engine noise in the vicinity of airports continues to be of paramount importance. Jet exhaust nozzle chevron systems are a proven noise reduction technology, but much is yet to be learned about their parametric design space and a tradeoff between noise reduction at takeoff/landing and thrust loss at cruise has slowed their incorporation into production engines ${ }^{1}$. Chevrons produce a scalloped trailing edge to the nozzle and protrude into the flow, increasingly from root to tip, in the flow direction. All model scale noise reduction and/or flow studies involving chevrons have been performed using static chevron technology, where the geometry and resulting flow immersion is predetermined and invariant ${ }^{2-12}$. These studies typically included some parametric investigation of chevron number, geometry, immersion, etc. However, detailed parametric investigations using static chevrons were not possible because of the high cost of fabricating and testing separate nozzle systems. Computational studies are similarly limited in their ability to investigate the parametric design space.

One means of simultaneously addressing some parametric design issues and the tradeoff of noise reduction and thrust penalty is the development of deployable (active) chevrons. The active chevron application appears to be ideal for shape memory alloy (SMA) actuation technology because SMA actuators can be thermally activated, they produce large force and stroke, and the quasi-static nature of active chevron requirements alleviates issues associated with the limited frequency response of the thermoelastic shape memory effect. Shape memory alloys exhibit a phase transformation that is driven by temperature and stress. The thermally induced phase transformation is responsible for the well-known

\footnotetext{
*t.l.turner@larc.nasa.gov; phone 1757 864-3598; fax 1757 864-8823; Mail Stop 463; http://stab.larc.nasa.gov

***.h.cabell@1arc.nasa.gov; phone 1757 864-5266; fax 1757 864-8823; Mail Stop 463; http://stab.larc.nasa.gov

†.j.cano@larc.nasa.gov; phone 1757 864-3951; fax 1757 864-8312; Mail Stop 226

* g.a.fleming@larc.nasa.gov; phone 1757 864-6664; fax 1757 864-8315; Mail Stop 493
} 
shape memory effect that is of primary interest in this study. Shape memory alloys can recover a large strain by this effect when heated in an unconstrained configuration and generate large forces when this recovery is constrained. Thus, the general concept for a SMA enabled active chevron entails deploying the chevron under the actuation authority of prestrained SMA actuators.

SMA actuators can be employed in various ways to enable deployable chevrons. The only SMA-enabled active chevron concept known from the literature, other than the work of the present authors, was reported by Calkins and Butler ${ }^{13}$ and Mabe et al. ${ }^{14,15}$. That concept involves the use of Nitinol bender elements that work against a metallic or composite main structure to provide immersion control. Previous work at NASA Langley Research Center (LaRC) has demonstrated various structural control concepts via SMA hybrid composite (SMAHC) laminates ${ }^{16-18}$. In all cases, prestrained Nitinol actuators were embedded in a composite during lamination and restrained during elevated temperature cure. The active chevron concept considered in this study consists of Nitinol actuators embedded on one side of the middle surface of a laminated composite. Thus, thermal excitation causes the actuators to attempt recovery of the prestrain under the constraint of the bond to the host material. This asymmetry in thermal stress causes a moment that deflects the structure out of plane to the immersed configuration. The force developed in the host composite due to elastic strain during deflection is used to restore the structure to the retracted position.

Related research involving the shape/deflection control of cantilever composite beams by embedded SMA actuation has been reported in the literature. Bruck, Moore, and Valentine ${ }^{19}$ developed a beam bending concept involving polyurethane matrix materials by opposing one-way trained SMA actuators. Kim, Park, and Goo ${ }^{20}$ investigated the effects of elastic tailoring, e.g., composite ply angles, on bend and twist deformations of composite beams. Chandra ${ }^{21}$ reported results of SMA bender elements embedded in composite beams for delivering bend and twist authority to composite rotorcraft blades. Baz and $\mathrm{Ro}^{22}$ also incorporated bender elements within sleeves on the neutral axis of composite beams to control bending deflections without incurring the effects of in-plane stress.

Previous work by the present authors demonstrated the feasibility of the active SMAHC chevron concept ${ }^{23-25}$. That work also provided the first shape control experimental validation for a recently commercialized (MSC.Nastran and ABAQUS) constitutive model for SMAHC materials and structures ${ }^{25-28}$. However, deflection performance of the SMAHC chevron fell short of the requirement and shortcomings in the fabrication approach were identified. The objectives of the present work are to design (via the validated numerical tool) a SMAHC chevron that meets the performance requirements, develop a refined fabrication approach for SMAHC chevrons that meets the performance requirements with predictable/repeatable performance, perform bench top testing of the refined chevron prototype, and test the performance of the SMAHC chevron prototype in flow conditions representative of the jet engine environment.

Although autonomous chevrons are attractive and perhaps required for the most efficient operation in service, it is anticipated that active control may be desirable or required in some applications. Furthermore, the near term objective of this work is to enable parametric studies in the laboratory to investigate effects such as variable immersion depth and circumferential distribution for optimal jet noise reduction. Thus, the present study will focus on chevron systems at model scale and provisions are made to electrically activate the SMA actuators to enable active control. The chevron concept presented in this study lends itself to electrical and/or autonomous environmental activation for versatility in planned laboratory parametric studies and potentially for in-flight optimization of a full-scale concept.

\section{SMAHC CHEVRON FABRICATION}

A picture of static chevrons on the core and bypass nozzles of a jet engine simulator installed in the NASA LaRC Low Speed Aeroacoustic Wind Tunnel (LSAWT) is shown in Figure 1 . The model is approximately $1 / 10^{\text {th }}$ scale with the bypass nozzle having 14 chevrons around the circumference, incorporates the effects of a pylon, and has a radius of 4.865 inches $(12.357 \mathrm{~cm})$ at the root of the chevrons. Although the nozzle thickness is continuously tapered to the root of the chevrons, the chevron thickness is constant from root to tip. The static immersion of the chevrons is approximately 0.050 inches $(0.127 \mathrm{~cm})$ without flow loading effects and was specified as the result of previous numerical and experimental studies. The present effort is focused on developing active chevron technology for the bypass nozzle of a similar engine simulator by detailed study of individual chevrons. As a first step, the technology development is aimed at designing, fabricating, and demonstrating a viable chevron concept, so all subsequent discussion will pertain to flat chevrons, i.e., without the cylindrical radius of curvature. 
Previous work at NASA LaRC presented a fabrication approach, test results, and validation of a numerical model for a SMAHC chevron concept with a single embedded actuator assembly ${ }^{23,25}$. It was found that the single actuator assembly provided insufficient actuation authority and limitations of the fabrication approach dictated development of a new procedure for embedding multiple actuators. Numerical work subsequent to the previous study indicated that a dual actuator assembly configuration was sufficient to achieve the chevron tip deflection goal of 0.050 inches $(0.127 \mathrm{~cm})$. The requirements for electrical activation of the SMA actuators and for a clean trailing edge mandated electrical continuity of the actuator(s) within the chevron and actuator ingress/egress points at the chevron root. These constraints were accommodated in the fabrication approach by incorporating joints between two layers of Nitinol within the laminate to provide for electrical continuity. A schematic of the SMAHC chevron concept with dual actuator assemblies incorporating this internal joint is shown in Figure 2. The section schematic represents a section through SMA actuators embedded parallel to and on one side of the chevron centerline, which demonstrates the asymmetric actuator placement in the thickness direction to induce bending.

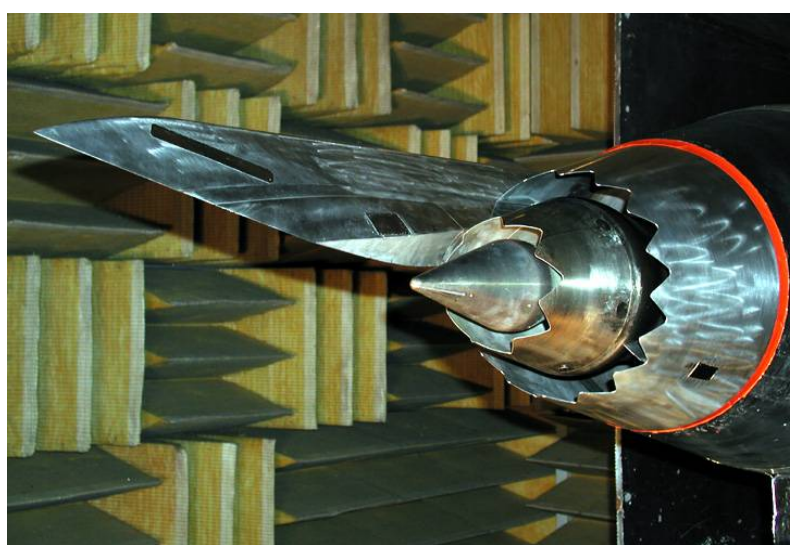

Figure 1: Static chevron scale nozzle model nozzle.

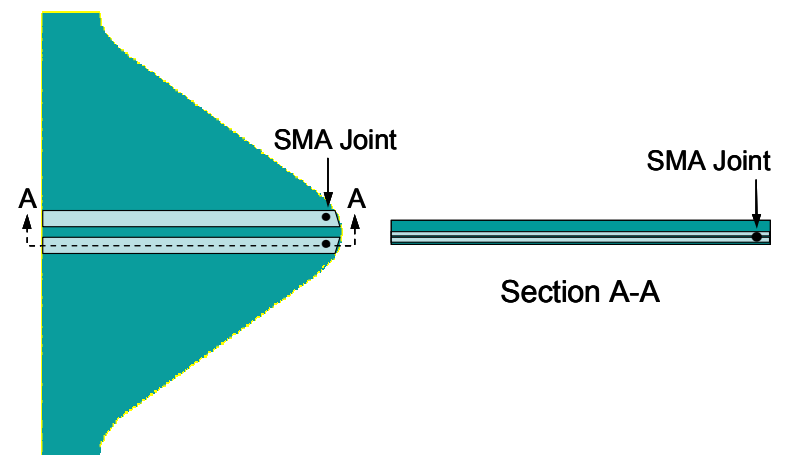

Figure 2: Schematic of the SMAHC chevron concept.

The general fabrication process that was employed in the present study consists of lamination of oversized pre-preg layers, consolidation by vacuum hot press cure, and machining to final dimensions. Lamination of oversize layers was performed, in lieu of die-cut net-shape layers, to take advantage of existing molds and to allow for the most flexibility in planform geometry and lay-up/cure tooling. Vacuum hot press processing enabled rapid fabrication and high throughput, although this is offset somewhat in this case by the requirement for machining. Details of the fabrication process are clearer in the following description of the materials involved and a representative fabrication sequence.

A SMAHC material system consisting of glass-epoxy unidirectional pre-impregnated (pre-preg) tape and Nitinol ribbon was selected for the present study. This material combination was selected because of several favorable properties and familiarity from previous experience. The glass-epoxy matrix material offers electrical isolation for resistive heating of the SMA actuators and affords visual flaw detection. Pre-preg material is available in thin layers and affords precise control over directional stiffness. The glass-epoxy material is an S2-glass/3501-6 resin material system with a nominal cured ply thickness of 0.004 inches $(0.01 \mathrm{~cm})$. A Nitinol alloy was selected due to its electrical resistance, shape memory capability, and availability. The ribbon (rectangular cross section wire) configuration simplified the fabrication procedure, by minimizing the number of actuators, and the mechanical/electrical connectivity of the structure in service. The Nitinol ribbon was obtained with nominal cross section dimensions of $0.090 \times 0.006$ inches $(0.229 \times 0.015 \mathrm{~cm})$ and transformation temperatures, as determined by differential scanning calorimetry, of $\mathrm{A}_{\mathrm{s}}=113^{\circ} \mathrm{F}\left(45^{\circ} \mathrm{C}\right), \mathrm{A}_{\mathrm{f}}=140^{\circ} \mathrm{F}\left(60^{\circ} \mathrm{C}\right)$, $\mathrm{M}_{\mathrm{s}}=62.6^{\circ} \mathrm{F}\left(17^{\circ} \mathrm{C}\right)$, and $\mathrm{M}_{\mathrm{f}}=32^{\circ} \mathrm{F}\left(0^{\circ} \mathrm{C}\right)$.

The Nitinol ribbon material was prestrained (elongated) $4 \%$ and lightly sandblasted to remove the oxide layer for improved Nitinol-Nitinol joining and Nitinol-resin adhesion purposes. Pairs of the Nitinol ribbon were aligned and spot welded in an Argon atmosphere at a location along the length of the actuators convenient for placement at the intended chevron tip during the lamination process. The joint actually consisted of three consecutive welds approximately 0.050 inches $(0.127 \mathrm{~cm})$ apart and spanning approximately 0.1 inches $(0.254 \mathrm{~cm})$ of the actuator assembly length. A representative spot welding process was observed with an infrared camera and it was found that the thermal pulse traveling away from the weld site had a maximum temperature of approximately $90^{\circ} \mathrm{F}\left(32.2^{\circ} \mathrm{C}\right)$ closest to the weld and 
dissipated completely at a distance of less than 0.375 inches $(0.953 \mathrm{~cm})$ from the weld site. Thus, it is anticipated that the spot welding process had minimal effect on the Nitinol actuators, except in the immediate vicinity of the welds.

It was previously determined that material dimensions and chevron design constraints required the use of at least five plies of glass-epoxy. Plies of the glass-epoxy material were cut to fit an existing $2 \times 2$ inch $(5.08 \times 5.08 \mathrm{~cm})$ vacuum hot press mold and lamination was performed according to the following sequence: $(-45 /+45 / 90 / \mathrm{SMA} /+45 / \mathrm{SMA} /-45)$. The upper $+45^{\circ}$ layer was cut into 1.4 inch $(3.556 \mathrm{~cm})$ and 0.6 inch $(1.524 \mathrm{~cm})$ segments and the 0.6 inch $(1.524 \mathrm{~cm})$ segment was added to the $-45 /+45 / 90$ lay-up at the outboard edge prior to installing the actuator assemblies. The actuator assemblies were positioned symmetrically about the lay-up centerline with an outside-to-outside edge dimension of 0.25 inches $(0.635 \mathrm{~cm})$. Additionally, the actuators were positioned with the spot welds resting on the 0.6 inch $(1.524 \mathrm{~cm})$ $+45^{\circ}$ segment with the innermost weld adjacent to the inner edge of the segment, as shown in Figure 3 . The 1.4 inch $(3.556 \mathrm{~cm})+45^{\circ}$ segment was inserted between the two strands of Nitinol in each actuator assembly and worked as close to the first weld as possible, thereby making a close fit with the 0.6 inch $(1.524 \mathrm{~cm})+45^{\circ}$ segment. The final $-45^{\circ}$ ply was added to the lay-up and the assembly was installed in the mold with an orientation that placed the intended root edge of the chevron against a resin dam, as shown in Figure 4. The large mold depth is an artifact of its previous use and not necessary for the present fabrication process. Note that a layer of polyimide release film and bleeder cloth was placed beneath and on top of the laminate during insertion in the mold. The Nitinol actuators protruded through a slit in the resin dam on the chevron root side of the mold and directly from the mold mating surfaces on the opposite side. Gripping assemblies rigidly restrained the Nitinol on both sides of the mold.

The laminate was subjected to the cure cycle recommended by the pre-preg manufacturer; heated from room temperature to $250^{\circ} \mathrm{F}(121.1)^{\circ} \mathrm{C}$ at $3-5^{\circ} \mathrm{F} / \mathrm{min}\left(1.7-2.8^{\circ} \mathrm{C} / \mathrm{min}\right)$, held for 15 minutes at $250^{\circ} \mathrm{F}(121.1)^{\circ} \mathrm{C}, 85 \mathrm{psi}(586 \mathrm{kPa})$ of pressure was applied, held at $250^{\circ} \mathrm{F}(121.1)^{\circ} \mathrm{C}$ and $85 \mathrm{psi}(586 \mathrm{kPa})$ for an additional 45 minutes, heated again to $350^{\circ} \mathrm{F}\left(176.7^{\circ} \mathrm{C}\right)$ at $3-5^{\circ} \mathrm{F} / \mathrm{min}\left(1.7-2.8^{\circ} \mathrm{C} / \mathrm{min}\right)$ while holding $85 \mathrm{psi}(586 \mathrm{kPa})$, held at $350^{\circ} \mathrm{F}\left(176.7^{\circ} \mathrm{C}\right)$ and $85 \mathrm{psi}(586 \mathrm{kPa})$ for 2 hours, cooled to room temperature at $3-5^{\circ} \mathrm{F} / \mathrm{min}\left(1.7-2.8^{\circ} \mathrm{C} / \mathrm{min}\right)$ while holding $85 \mathrm{psi}(586 \mathrm{kPa})$, and the pressure was released at room temperature. The resulting consolidated laminate is shown in Figure 5. The resin dam provided a reference edge for machining the laminate to final chevron dimensions, the result of which is shown in Figure 6. The Nitinol leads remaining at the root edge of the chevron were copper plated to enable soldering to the leads and to improve contact-type electrical connections.

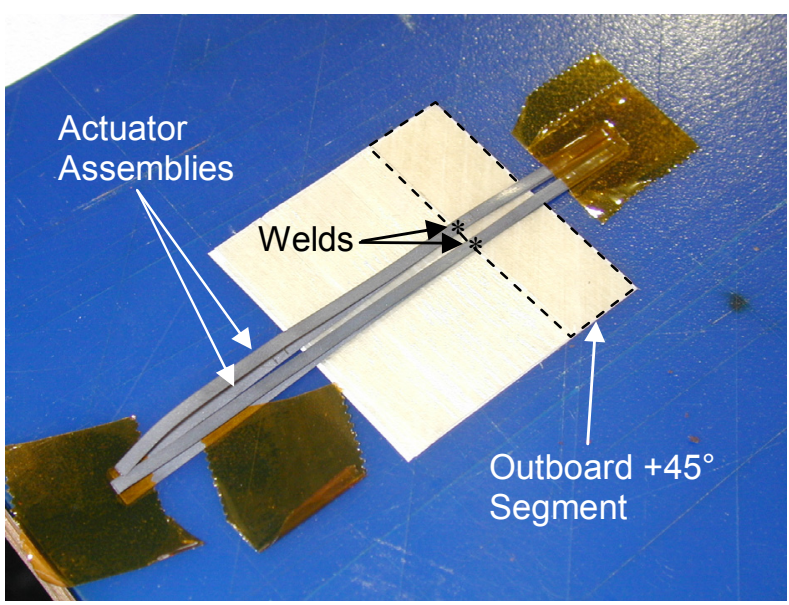

Figure 3: Actuator assemblies placed on lay-up.

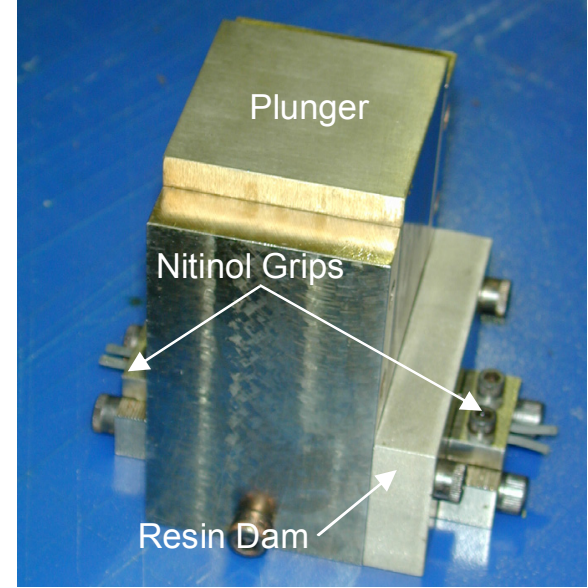

Figure 4: Finished lay-up installed in mold.

Although the laminate is asymmetric due to the embedded Nitinol ribbon, no warping of the laminate results after cure because the restraint on the actuators prevents recovery of the prestrain and participation in generation of a thermal moment during cooling. The consolidated laminate has a thickness of approximately 0.025 inches $(0.0635 \mathrm{~cm})$ in the region away from the Nitinol and 0.028 inches $(0.0711 \mathrm{~cm})$ in the region with the Nitinol. It is apparent that there is significant compaction of the glass-epoxy in the vicinity of the Nitinol due to the vacuum hot press processing approach. Conversely, the region away from the Nitinol exhibits a thickness greater than the nominal thickness indicated by the vendor. 


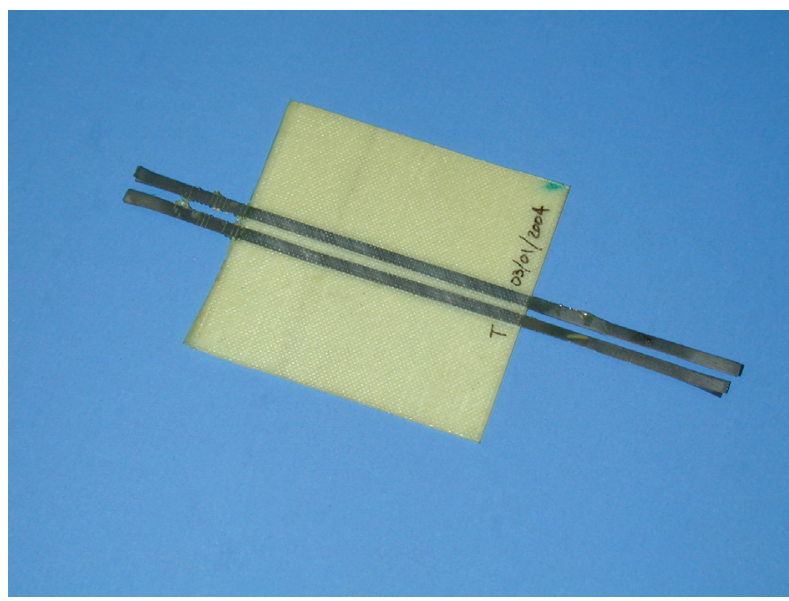

Figure 5: Consolidated SMAHC laminate.

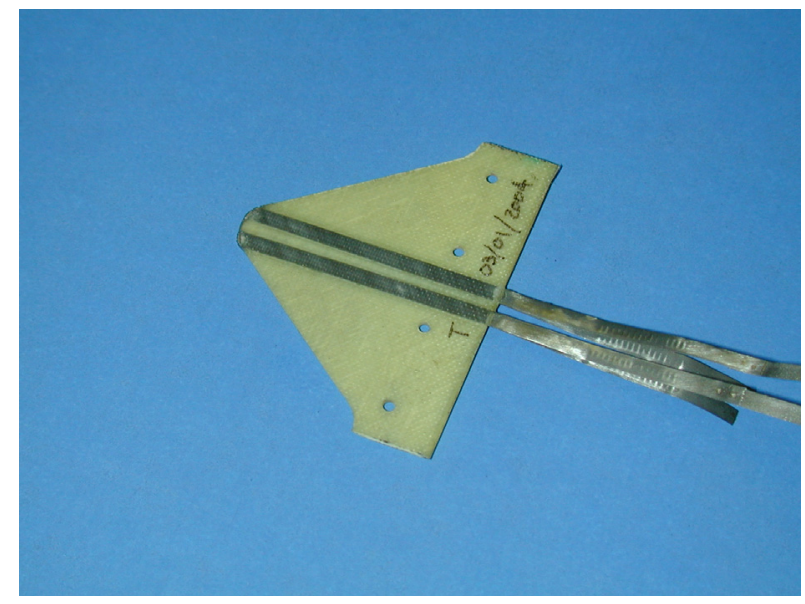

Figure 6: SMAHC chevron.

\section{BENCH TOP TESTING}

The chevron fabricated by the process described in the previous section was tested on the bench top to confirm baseline performance, to provide experimental data under a tightly controlled environment for further analysis validation, and to thermally cycle the chevron to render it thermomechanically stable.

\subsection{Experimental Arrangement}

The test system, shown in Figure 7, consisted of an optical bench for accurate component placement, a digital infrared (IR) camera for full-field temperature measurement, a projection moiré interferometry (PMI) system for full-field out-ofplane displacement measurement, a laser displacement transducer (LDT) for single point displacement measurement, and a LabVIEW-based test control and data acquisition system. The laser displacement transducer was a Keyence Model LK-081 and has the following specifications; measurement range 1.18 inches $(3 \mathrm{~cm})$ and resolution $1.2 \mathrm{e}-6$ inches $(3 \mu \mathrm{m})$. The IR camera was a FLIR SC2000 that had an un-cooled micro-bolometer focal plane array detector with an array size of $320 \times 240$ pixels. The accuracy of the IR camera was $\pm 2 \%$ and the digital resolution is 14-bit. The IR camera was used on a $32-932^{\circ} \mathrm{F}\left(0-500^{\circ} \mathrm{C}\right)$ range, which gives a temperature resolution of $0.05^{\circ} \mathrm{F}\left(0.03^{\circ} \mathrm{C}\right)$. The IR measurements were calibrated by setting the target emissivity to the total hemispherical emissivity of the chevron, which had been measured previously. The PMI video camera was a $1300 \times 1030$ pixel (width $\times$ height) camera equipped with a standard Nikon 105-mm lens. Video from the camera was digitized to 8-bits using a video frame grabber installed in a PCcompatible computer. The camera/lens combination yielded a $2.875 \times 2.250$ inch field-of-view (width $\times$ height) with a spatial resolution of $2.12 \mathrm{e}-3$ inches/pixel $(5.39 \mathrm{e}-3 \mathrm{~cm} / \mathrm{pixel})$. The PMI system projector was used to project a series of equi-spaced, parallel lines with a nominal grid line pitch of 0.026 inches $(0.066 \mathrm{~cm})$ onto the chevron surface. The PMI system was calibrated over a range that exceeded the anticipated range of chevron deformation and achieved a nominal random measurement error of \pm 0.0012 inches $( \pm 1 \sigma)$, uniformly distributed throughout the PMI system field-of-view. This random uncertainty was smaller than the estimated chevron surface roughness. The IR and PMI system cameras were positioned approximately 30 inches $(76 \mathrm{~cm})$ from the chevron. The LDT was positioned on the side opposite the IR and PMI cameras and normal to chevron surface near the tip.

A close-up view of the chevron mounted to the support post is shown in Figure 8. The side of the chevron facing the IR and PMI systems was painted white to provide an opaque and diffuse scattering surface for the PMI system, which resulted in a total hemispherical emissivity of 0.9 for calibration of the IR data. The chevron was configured such that the actuators were closest to the painted surface of the chevron and the chevron bent toward the IR and PMI cameras upon actuation. The chevron was fastened to the post and mechanical and electrical connections to the Nitinol actuator assemblies were made in the grip assembly attached at the back of the mounting post. The grip assembly consisted of electrically separated copper-plated contacts embedded in a Garolite G10 (fiberglass) carrier and a clamping bar with copper plating on the grip face, as shown in the inset of Figure 8. The G10 carrier electrically isolated the grip assembly from the support post. A layer of Kapton tape insulated the two Nitinol leads of each actuator assembly from one 
another, starting at the edge of the chevron and ending at the back edge of the clamping bar (not shown in Figure 8). Thus, an electrical power connection was made to the bottom lead of each actuator assembly, indicated by $+/-$ in Figure 8 , and continuity was provided by the spot welds within the chevron and by the copper plated clamping bar in the grip assembly. All of the Nitinol ribbon was configured electrically in series in this manner.

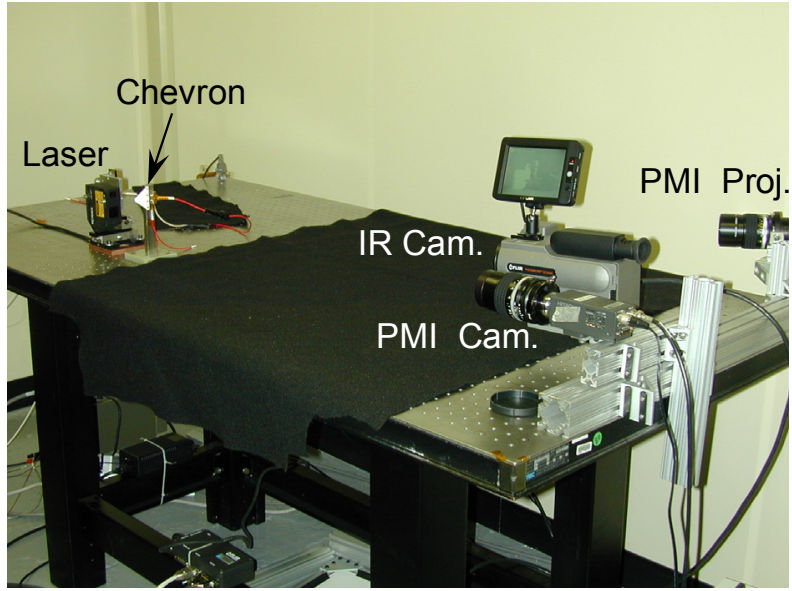

Figure 7: Overview of chevron test system.

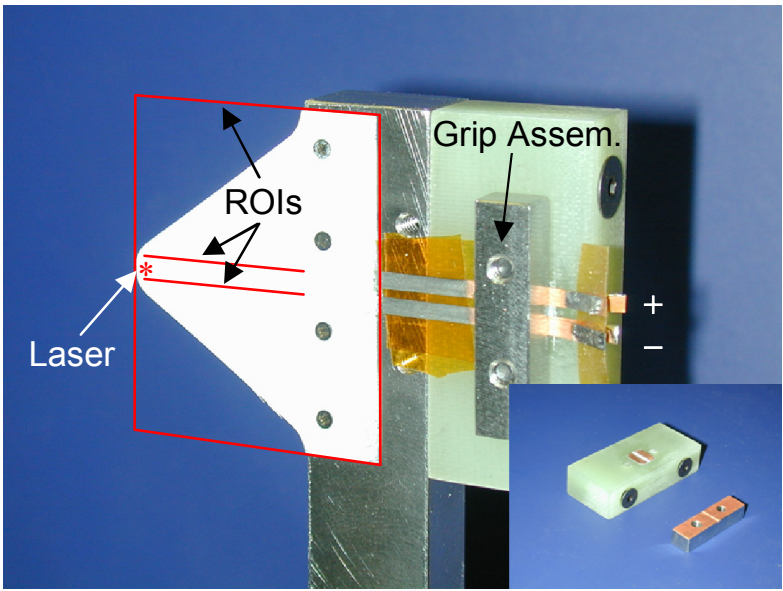

Figure 8: Close-up of chevron specimen mounted on post.

The LabVIEW control and data acquisition system consisted of a PC configured with a National Instruments (NI) PCI1424 frame-grabber card, a NI PCI-6052E multifunction I/O card, and a NI PCI-GPIB card. The frame-grabber and RS232 connections established image acquisition and communication, respectively, with the IR camera. The multi-function I/O card, which was interfaced to a NI SC-2345 with SCC-series signal conditioning modules, performed the function of analog data acquisition from the LDT and thermocouples. The multifunction I/O configuration was also used to provide a TTL trigger signal from the LabVIEW system to the PMI data acquisition system. Feedback control was achieved via a proportional-integral type controller with an average temperature from the IR measurements as the control metric. Power was supplied to the chevron by a HP 6652A DC power supply operated in current control mode by direct GPIB commands from the LabVIEW system.

The laser spot was positioned at a point on the chevron centerline and approximately 0.050 inches from the tip. This location is indicated on the opposite side of the chevron in Figure 8 by the red asterisk and is close to the location of the first centerline node off the tip of the finite element model that will be discussed in the next subsection. Regions of interest (ROI) including a rectangle encompassing the entire chevron and two lines along the centerline of each Nitinol actuator assembly from the tip of the chevron to the edge of the support post were defined in the LabVIEW data acquisition and control system, as shown schematically in Figure 8. Thermal cycles were performed on the chevron by prescribing a setpoint distribution for the average temperature of the top line ROI consisting of $10^{\circ} \mathrm{F}\left(5.6^{\circ} \mathrm{C}\right)$ increments from room temperature to $250^{\circ} \mathrm{F}\left(121.1^{\circ} \mathrm{C}\right)$ and back to room temperature. IR data was collected continuously for control purposes, but only recorded at the setpoints. The analog voltage and PMI data were also recorded at the setpoints, the latter coming as the result of the TTL trigger pulses. The PMI system acquired 10 images and averaged them at each setpoint for off-line processing.

\subsection{Numerical Modeling}

A thermoelastic model for SMA and SMAHC materials was recently implemented in the commercial finite element (FE) codes MSC.Nastran and ABAQUS. Additional detail about the constitutive model and its implementation in the commercial codes can be found in references $26-28$.

A FE model of the active SMAHC chevron was developed in MSC.Patran for pre-/post-processing. The chevron geometry was meshed using 2000 quadrilateral (type CQUAD4/S4 in MSC.Nastran/ABAQUS) and 48 triangular (type CTRIA3/S3 in MSC.Nastran/ABAQUS) shell elements, as shown in Figure 9. Note that the mesh was constructed such that the width of each Nitinol actuator assemblies constitutes four element widths. Thus, the red elements are comprised of two layers of Nitinol in addition to the five layers of glass-epoxy (-45/45/90/SMA/45/SMA/-45) and the blue elements 
have a lamination of glass-epoxy layers only (-45/45/90/45/-45). The Nitinol layers in the SMAHC elements have an orientation angle of $0^{\circ}$. Recall that the glass-epoxy plies surrounding the Nitinol ribbon exhibit significant compaction during cure. The layer thickness distribution was modeled by dividing the measured thickness in the region away from the Nitinol evenly between the 5 glass-epoxy layers or 0.005 inches $(0.0127 \mathrm{~cm})$ per layer. The thickness of the Nitinol layers was taken to be unchanged at 0.006 inches $(0.0152 \mathrm{~cm})$ per layer and the balance of the thickness in the Nitinol region was distributed evenly amongst the 5 glass-epoxy layers or 0.0032 inch $(0.0081 \mathrm{~cm})$ per layer.

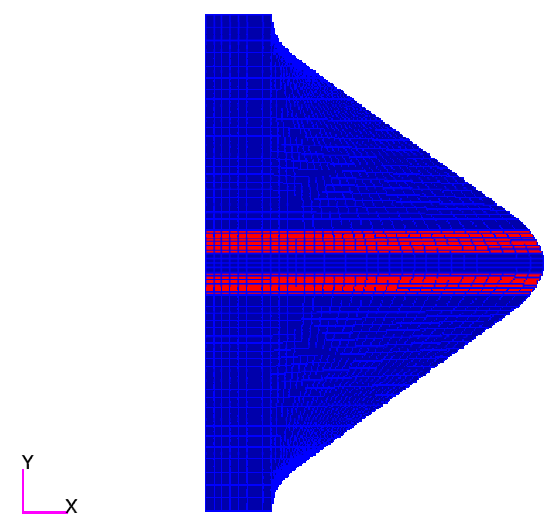

Figure 9: SMAHC chevron geometry and FE mesh.

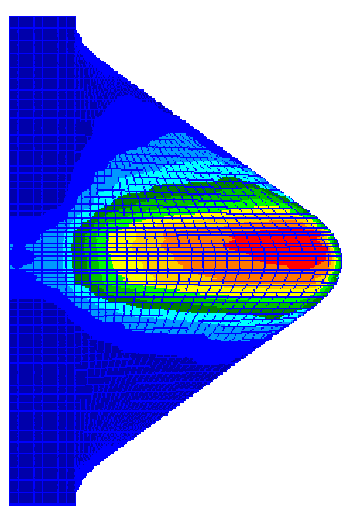

Figure 10: Measure temp. distr. interpolated onto FE mesh.

Thermomechanical characterization tests had been previously performed on the particular Nitinol ribbon material used in this study. However, properties specific to the glass-epoxy matrix material used in this study were not available, so approximate properties from a similar material system were used in the numerical predictions of the chevron performance. The temperature dependent orthotropic properties that were used in this study to model the Nitinol and glass-epoxy materials are shown in Table 1.

Table 1: Orthotropic material properties for glass-epoxy and Nitinol, secant CTE data presented with $\mathrm{T}_{\text {ref }}=70^{\circ} \mathrm{F}$.

\begin{tabular}{|c|c|c|c|c|c|c|c|c|c|c|c|}
\hline \multirow[b]{2}{*}{$\mathrm{T},{ }^{\circ} \mathrm{F}$} & \multicolumn{6}{|c|}{ Glass-Epoxy } & \multicolumn{5}{|c|}{ Nitinol } \\
\hline & $\alpha_{1}, /{ }^{\circ} \mathrm{F}$ & $\alpha_{2}, /{ }^{\circ} \mathrm{F}$ & $\mathrm{E}_{1}, \mathrm{psi}$ & $\mathrm{E}_{2}, \mathrm{psi}$ & $\mathrm{G}_{12}, \mathrm{psi}$ & $v_{12}$ & $\alpha_{1}, /{ }^{\circ} \mathrm{F}$ & $\alpha_{2}, /{ }^{\circ} \mathrm{F}$ & $E_{1}, E_{2}, p s i$ & $\mathrm{G}_{12}, \mathrm{psi}$ & $v_{12}$ \\
\hline 60 & $2.90 \mathrm{E}-06$ & $6.00 \mathrm{E}-06$ & $7.15 \mathrm{E}+06$ & $2.90 \mathrm{E}+06$ & $1.40 \mathrm{E}+06$ & 0.29 & $3.67 \mathrm{E}-06$ & $3.67 \mathrm{E}-06$ & $3.94 \mathrm{E}+06$ & $1.52 \mathrm{E}+06$ & 0.3 \\
\hline 80 & $3.07 \mathrm{E}-06$ & $6.84 \mathrm{E}-06$ & $7.15 \mathrm{E}+06$ & $2.90 \mathrm{E}+06$ & -06 & 0.29 & & $3.67 \mathrm{E}-06$ & $3.60 \mathrm{E}+06$ & +06 & 0.3 \\
\hline 100 & $3.39 \mathrm{E}-06$ & $8.73 \mathrm{E}-06$ & $7.13 E+06$ & $2.82 \mathrm{E}+06$ & $1.34 \mathrm{E}+06$ & 0.29 & $-1.20 \mathrm{E}-05$ & $3.67 \mathrm{E}-06$ & $2.91 \mathrm{E}+06$ & $1.12 \mathrm{E}+06$ & 0.3 \\
\hline 120 & 3. & $1.03 \mathrm{E}-05$ & 7.1 & 66 & 66 & 0.29 & $-2.0^{2}$ & -06 & $4.55 \mathrm{I}$ & 06 & 0.3 \\
\hline 140 & $3.71 \mathrm{E}-06$ & 1.1 & $7.08 \mathrm{E}+06$ & $2.68 \mathrm{E}+06$ & 06 & 0.29 & -4.5 & $3.77 \mathrm{E}-06$ & $6.18 \mathrm{E}+06$ & +06 & 0.3 \\
\hline 160 & $3.72 \mathrm{E}-06$ & $1.17 \mathrm{E}-05$ & $7.07 \mathrm{E}+06$ & $2.58 \mathrm{E}+06$ & -06 & 0.29 & $-4.8^{\prime}$ & E-06 & $7.96 \mathrm{E}+06$ & +06 & 0.3 \\
\hline 180 & $3.70 \mathrm{E}-06$ & 1.19E-05 & $7.06 \mathrm{E}+06$ & 2.47 & 1.15 & 0.29 & -4. & 4.24E-06 & $9.31 \mathrm{E}+06$ & +06 & 0.3 \\
\hline 200 & $3.67 \mathrm{E}-06$ & $1.20 \mathrm{E}-05$ & $7.05 \mathrm{E}+06$ & $2.35 \mathrm{E}+06$ & 1.10 & 0.29 & $-4.99 \mathrm{E}-05$ & $4.51 \mathrm{E}-06$ & $9.00 \mathrm{E}+06$ & $3.46 \mathrm{E}+06$ & 0.3 \\
\hline 220 & $3.65 \mathrm{E}-06$ & $1.20 \mathrm{E}-05$ & $7.05 \mathrm{E}+06$ & 2.22 & 9.80 & 0.29 & $-4.56 \mathrm{E}-05$ & $4.73 \mathrm{E}-06$ & $9.54 \mathrm{E}+06$ & $3.67 \mathrm{E}+06$ & 0.3 \\
\hline 240 & 3.6 & 1.2 & $7.04 \mathrm{E}+06$ & 2.0 & & 0.29 & -4.0 & E-06 & $1.01 \mathrm{E}+07$ & +06 & 0.3 \\
\hline 260 & $3.67 \mathrm{E}-06$ & $1.22 \mathrm{E}-05$ & $7.05 \mathrm{E}+06$ & 1.95 & & 0.29 & $-3.72 \mathrm{E}-05$ & $5.02 \mathrm{E}-06$ & $1.03 \mathrm{E}+07$ & +06 & 0.3 \\
\hline 280 & $3.71 \mathrm{E}-06$ & $1.23 \mathrm{E}-05$ & $7.06 \mathrm{E}+06$ & $1.80 \mathrm{E}+06$ & $6.20 \mathrm{E}+05$ & 0.29 & $-3.51 \mathrm{E}-05$ & $5.12 \mathrm{E}-06$ & $1.01 \mathrm{E}+07$ & $3.89 \mathrm{E}+06$ & 0.3 \\
\hline 300 & $3.75 \mathrm{E}-06$ & $1.25 \mathrm{E}-05$ & $7.08 \mathrm{E}+06$ & $1.65 \mathrm{E}+06$ & $5.00 \mathrm{E}+05$ & 0.29 & $-3.31 \mathrm{E}-05$ & $5.21 \mathrm{E}-06$ & $9.97 \mathrm{E}+06$ & $3.83 \mathrm{E}+06$ & 0.3 \\
\hline
\end{tabular}

The boundary conditions in the bench top test configuration were modeled as follows. All six degrees of freedom (DOF) were constrained at the screw attachment nodal locations and at the base of the Nitinol strips at the edge of the chevron. The out-of-plane translational DOF were constrained over the entire mounting surface. The measured full-field temperature distribution at room temperature and at the three elevated temperature setpoints of $130^{\circ} \mathrm{F}\left(54.4^{\circ} \mathrm{C}\right), 190^{\circ} \mathrm{F}$ $\left(87.8^{\circ} \mathrm{C}\right)$, and $250^{\circ} \mathrm{F}\left(121.1^{\circ} \mathrm{C}\right)$ were interpolated onto the finite element nodal locations, as illustrated for the $250^{\circ} \mathrm{F}$ $\left(121.1^{\circ} \mathrm{C}\right)$ in Figure 10, and used as the initial and load temperature distributions in the analysis. Analysis input files for MSC.Nastran and ABAQUS were generated from the FE model in MSC.Patran. Nonlinear static analyses were performed with the increment-dependent thermal load defined by interpolation between the measured temperature distributions. 


\subsection{Experimental and Numerical Results}

The chevron was subjected to a total of 56 thermal cycles (tests) on the bench top. The maximum power consumption of the chevron in the course of these tests was nominally 3.5 Watts (1.6 volts @ $2.25 \mathrm{amps})$ at the peak setpoint temperature of $250^{\circ} \mathrm{F}\left(121.1^{\circ} \mathrm{C}\right)$. The deflection at the laser spot location (denoted as near-tip) versus setpoint temperature (average centerline temperature of the top actuator assembly) for the $1^{\text {st }}$ and $56^{\text {th }}$ thermal cycles is shown in Figure 11 . The expected decrement in actuation authority and narrowing of the hysteresis loop, as the system is trained in situ, is evident. Note that the chevron did not completely return to its original un-deflected shape subsequent to the first thermal cycle, thereby leaving slight curvature in the chevron and approximately 0.010 inches $(0.025 \mathrm{~cm})$ of tip deflection. The amount of additional permanent deformation decreased rapidly with thermal cycle and became insignificant beyond thermal cycle number 4 , leaving a total of approximately 0.015 inches $(0.038 \mathrm{~cm})$ of tip deflection relative to the undeflected shape. The chevron performance was very repeatable approaching 50 thermal cycles. The permanent deformation has implications for tests under representative flow conditions, as will be described in the next section. Although the stabilized maximum deflection at the near-tip location is $\sim 0.046$ inches $(0.117 \mathrm{~cm})$, the tip deflection objective of 0.050 inches $(0.127 \mathrm{~cm})$ has been achieved because the tip deflection is known from PMI measurements to be nominally 0.005 inches $(0.013 \mathrm{~cm})$ greater than the near-tip deflection. Also, there is additional actuation authority to be obtained at slightly higher temperatures, which will be demonstrated in the next section.

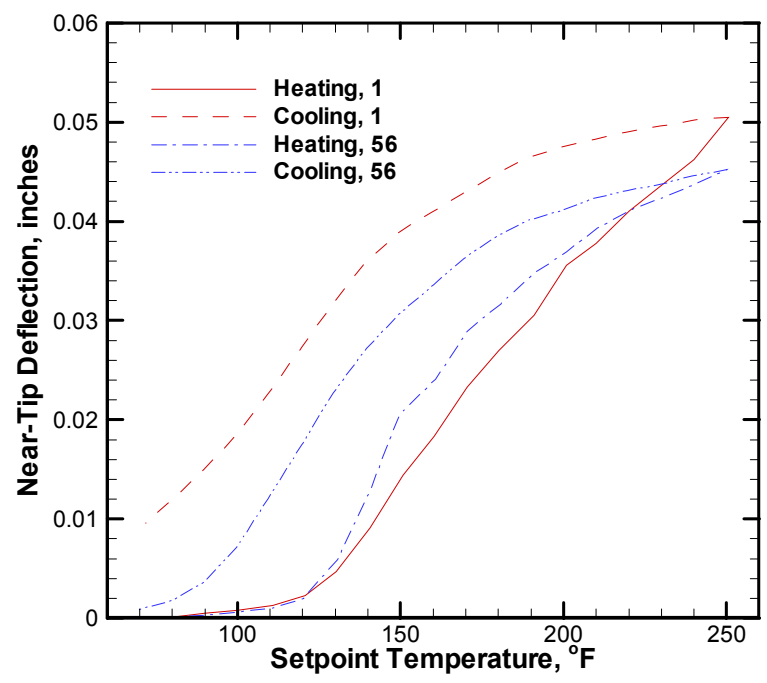

Figure 11: Laser spot location deflection versus setpoint temperature for the $1^{\text {st }}$ and $56^{\text {th }}$ thermal cycles.

Measured and predicted deflection at the near-tip location versus setpoint temperature for test number 1 is shown in Figure 12. It can be seen that the agreement between the measurements and predictions is excellent, the predictions from MSC.Nastran and ABAQUS being practically indistinguishable. Although the quality of the agreement is typical of all of the tests, it is noted that there was some variability in the observed discrepancies over the deflection range with test number. This variability is attributable to the large rotation (slope) near the chevron tip; recall the 0.005 inch $(0.013 \mathrm{~cm})$ difference between PMI near-tip and tip deflection results described above. Thus, even minor inconsistency in the location of the predicted and measured responses can lead to notable differences. There is some inherent variability in the location of the LDT and in the PMI processing for each test. Additionally, the LDT and PMI measurement locations move toward the tip as the chevron deflection increases, because rotation moves the chevron tip in the negative $\mathrm{x}$ direction while deflecting in the z-direction, which leads to systematic discrepancy in the comparisons manifested as slightly deteriorating agreement with increasing deflection. These observations are at least partly responsible for the differences between the LDT and PMI results and between the measured and predicted results. The permanent deformation described above also has implications for such deflection comparisons for thermal cycles greater than one, i.e., initial imperfections were not considered in the predictions. Corresponding results comparing measured and predicted centerline deflection profiles versus setpoint temperature for test number 1 are shown in Figure 13. The centerline profile is shown at ambient temperature and at three elevated temperatures; $130^{\circ} \mathrm{F}\left(54.4^{\circ} \mathrm{C}\right), 190^{\circ} \mathrm{F}\left(87.8^{\circ} \mathrm{C}\right)$, and $250^{\circ} \mathrm{F}\left(121.1^{\circ} \mathrm{C}\right)$. It can be seen that the predicted and measured results are in excellent agreement in both deflection amplitude and shape. Note that the PMI deflection data have been fit to remove variability due to surface roughness. 


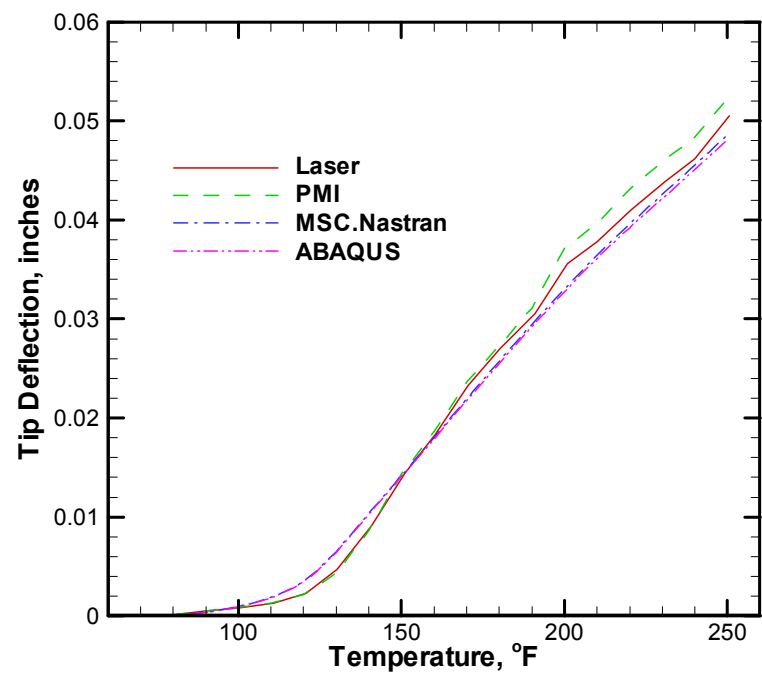

Figure 12: Measured and predicted deflection vs. temperature for test numbers 1 and 56.

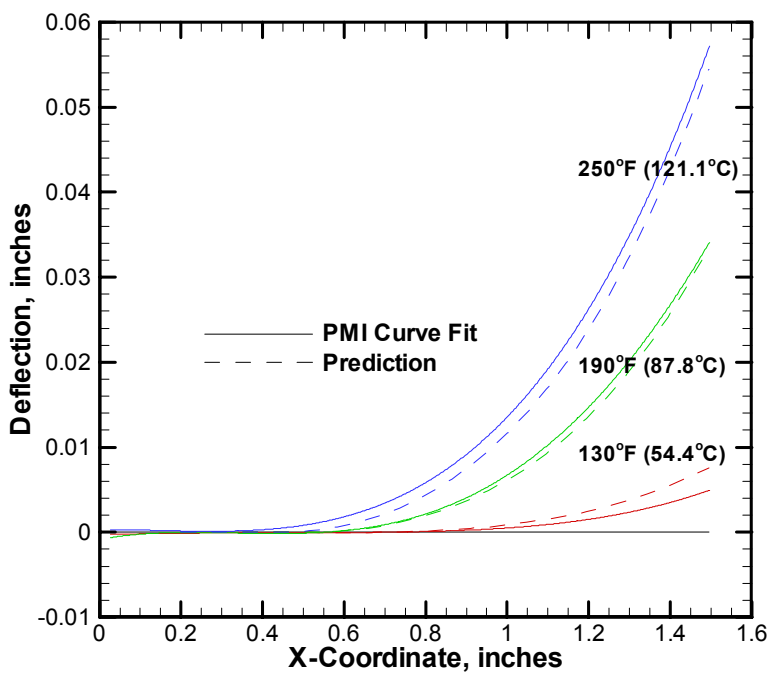

Figure 13: Measured and predicted centerline deflections at four temperatures for test number one.

\section{TESTING WITH REPRESENTATIVE FLOW CONDITIONS}

The chevron was further tested in the NASA LaRC Small Anechoic Jet Facility (SAJF) to explore nozzle integration issues and examine the effects of representative flow conditions on the chevron temperature distribution, power consumption, deflection performance, and deflection controllability.

\subsection{Experimental Arrangement}

The test apparatus consisted of the SAJF apparatus and flow controller, the chevron/nozzle/duct assembly, the IR and PMI systems, the LDT, and a MATLAB-based control and data acquisition system interfaced with the chevron instrumentation and a DC power supply. A top-view schematic of the overall SAJF test configuration is shown in Figure 14. The SAJF apparatus consisted of a heated and pressurized air supply system providing controlled flow conditions to a nozzle assembly, which draws entrained flow about the supply duct and exhausts into a semi-anechoic test cell. The test cell flow collector and exhaust fan maintained nominally ambient temperature and pressure conditions in the test cell. The PMI and IR systems were configured on an optical bench within the test cell at a distance of approximately 24 inches $(61 \mathrm{~cm})$ from the chevron apparatus mounted on the nozzle assembly. Upon actuation, the chevron deflected away from the IR and PMI systems, i.e., into the flow exhausting from the nozzle. The laser was positioned at the reference distance from the chevron by mounting it to a bracket attached to the nozzle assembly.

Details of the chevron and nozzle assembly are shown in Figure 15. Progressing in the flow direction, from left to right in the photo, the nozzle assembly consisted of a round $(6 \mathrm{inch}, 15.24 \mathrm{~cm}$ diameter) to square transition piece and a $2 \times 2$ inch $(5.08 \times 5.08 \mathrm{~cm})$ square nozzle. The chevron and stainless steel adapter assembly was mounted to the square nozzle. A three-sided plastic housing was also attached to the nozzle and provided the other three sides of flow containment over the length of the stainless steel adapter. A close-up view of the chevron-adapter assembly from the side opposite the flow is shown in Figure 16. Note that this picture was taken prior to painting this surface of the chevron white for the PMI measurements. Features of the chevron adapter include a recessed step at the trailing edge to mate with the chevron without flow disturbance, an electrically insulated trench for routing the power leads, and a copper plated clamping bar for gripping and providing electrical continuity to the Nitinol actuators. The chevron made a lap joint with the adapter with the Nitinol actuators protruding from the root of the chevron through a slit in the adapter and into the electrically insulated trench. A layer of Kapton tape separated the two Nitinol leads of each actuator assembly. All of the Nitinol was configured electrically in series in a manner similar to that achieved in the bench top tests. Power was connected to the bottom lead of each actuator assembly (indicated by $+/$-in Figure 16) and continuity was made within the chevron by the spot welds and across the two top leads of the actuator assemblies in the adapter by the clamping bar. The red 
asterisk in Figure 16 indicates the location of the laser spot on the other (flow) side of the chevron and approximately 0.055 inches $(0.140 \mathrm{~cm})$ from the tip.

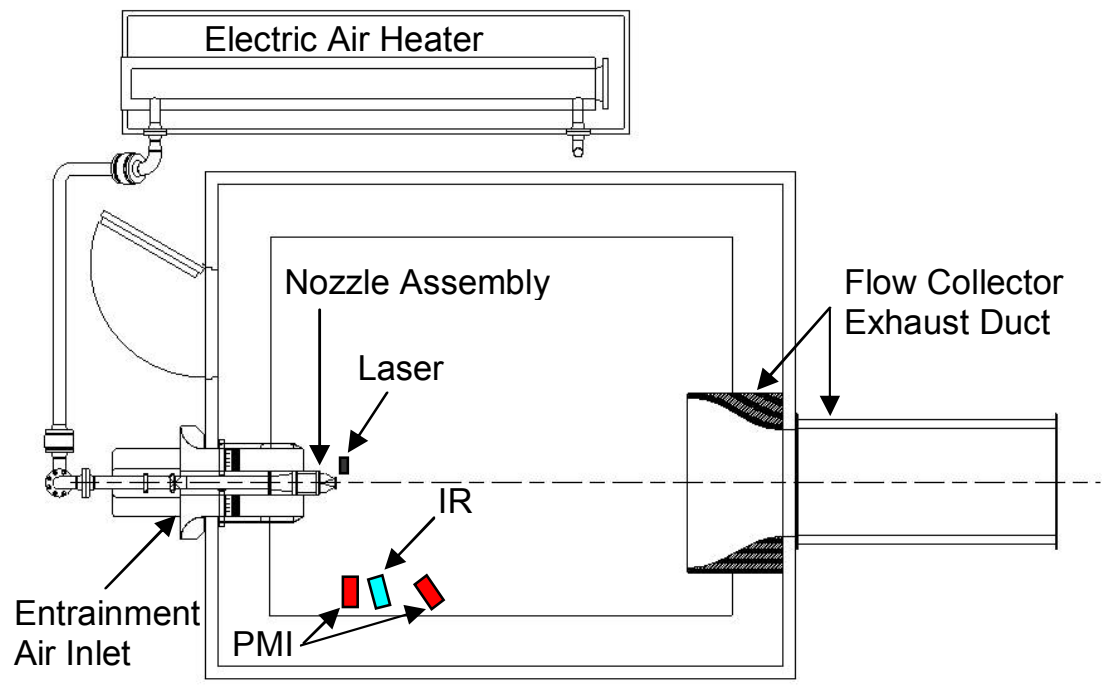

Figure 14: Top-view schematic of SAJF test configuration.

The chevron was instrumented with three pairs of back-to-back strain transducers, i.e., transducer pairs mounted at the same planform location but on opposite faces of the chevron. One pair of Luna EFPI fiber optic strain gages (type S-EAFSS-03-F) was attached at the chevron centerline. Another pair of fiber gages was attached at the upper outboard location. A pair of conventional (foil) gages (Micro-Measurements type EA-06-070LC-350) was mounted at the lower outboard location. A $36 \mathrm{AWG}(0.005 \mathrm{inch}, 0127 \mathrm{~cm}$ diameter $)$ type-T thermocouple was mounted in the vicinity of and at mid-span of the gage length of each strain transducer, as indicated in Figure 16 by TC1-TC6. Flow-side thermocouples are indicated by circled numbers and were located on the opposite side of the corresponding strain transducers than the thermocouples visible on the side opposite the flow in Figure 16. The strain instrumentation was included in this test to explore its use for active control, but the resulting strain measurements are not discussed in this study due to space limitations.

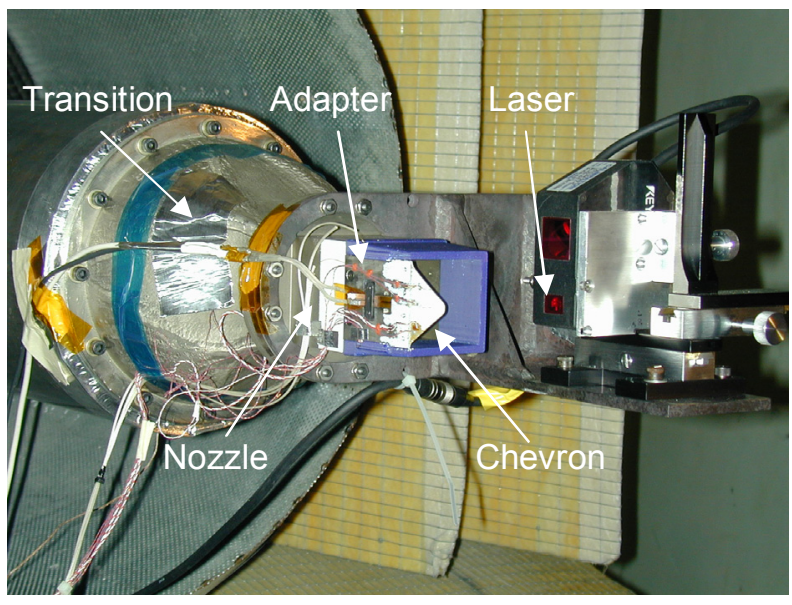

Figure 15: Detail of chevron-adapter assembly, nozzle, and transition to supply duct.

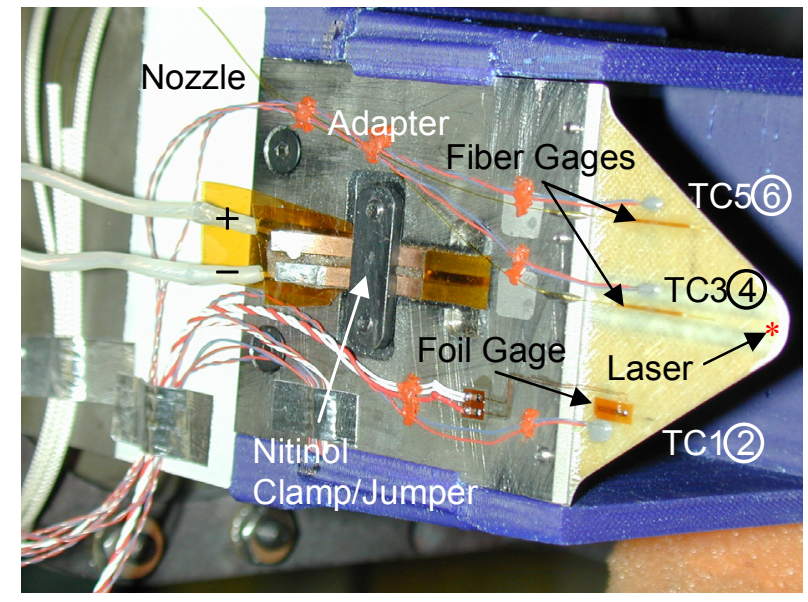

Figure 16: Detail of chevron instrumentation and power connectivity.

RC Electronics model 4120 modules conditioned the type-T thermocouple measurements. The MATLAB-based controller and data acquisition system consisted of an xPC real-time control system configured with a 64-channel, 16-bit analog to digital input card (United Electronic Instruments model PD2-MF-16-333/16H), and a 16 channel, 16-bit digital to analog output card (UEI PD2-AO-16/16). The xPC control system was interfaced to the strain, thermocouple, and 
laser instrumentation. Electrical power was supplied to the chevron by a HP 6652A DC power supply operated in current control mode and commanded by analog voltage from the MATLAB-based control system. Heating of the Nitinol actuators was done in either an open-loop or closed-loop mode. In open-loop mode, a specified current level was applied the actuators. In closed-loop mode, a proportional-integral controller with anti-windup ${ }^{29}$ was used to regulate the current applied to the actuators in order to drive the chevron to a specified tip immersion. The output of the LDT was used for the feedback measurement in closed-loop mode. The eventual chevron immersion control system will use a combination of thermocouple and strain measurements to estimate the chevron immersion, which will eliminate the need for a chevron tip position measurement (LDT or otherwise).

\subsection{Experimental Results}

The test conditions shown in Table 2 were established as representative of desirable engine configurations, i.e., bypass ratios (BPRs) 5 and 8 , at take-off (TO) and climb (CB) conditions. Terms in the table include nozzle pressure ratio (NPR), total temperature $\left(T_{t}\right)$, total pressure $\left(P_{t}\right)$, Mach number/temperature/velocity according to ideal gas relations $\left(\mathrm{M}_{\text {ideal }} / \mathrm{T}_{\text {ideal }} / \mathrm{V}_{\text {ideal }}\right)$, and the adiabatic wall temperature $\left(\mathrm{T}_{\mathrm{aw}}\right)$. Other quantities needed to produce the tabulated quantities are the ideal gas constant $640.2 \mathrm{in} / \mathrm{R}\left(287 \mathrm{~m}^{2} /\left(\mathrm{s}^{2} \cdot \mathrm{K}\right)\right)$, specific heat ratio of 1.4, flow area of $4 \mathrm{in}^{2}\left(25.8 \mathrm{~cm}^{2}\right)$, and ambient pressure of $14.7 \mathrm{psi}(101.36 \mathrm{kPa})$. Although flow at a higher total temperature, e.g., of $180^{\circ} \mathrm{F}\left(82.2^{\circ} \mathrm{C}\right)$, is more representative of actual bypass nozzle flow conditions, flow at a total temperature of $80^{\circ} \mathrm{F}\left(26.7^{\circ} \mathrm{C}\right)$ is the focus of this study because heat transfer between the flow and the chevron is governed by $\mathrm{T}_{\mathrm{aw}}$ and the $\mathrm{A}_{\mathrm{s}}$ temperature for the Nitinol alloy is $113^{\circ} \mathrm{F}\left(45^{\circ} \mathrm{C}\right)$. Thus, the $80^{\circ} \mathrm{F}\left(26.7^{\circ} \mathrm{C}\right)$ flow enables the entire chevron actuation authority to be effected by control stimulus and is expected to have negligible effect on jet noise simulation.

Table 2: Flow parameters associated with the tests performed on the chevron in the SAJF.

\begin{tabular}{ccccccccccc}
\hline Test Point & $\mathrm{NPR}$ & $\mathrm{T}_{\mathrm{t}},{ }^{\circ} \mathrm{R}$ & $\mathrm{T}_{\mathrm{t}},{ }^{\circ} \mathrm{F}$ & $\mathrm{M}_{\mathrm{ideal}}$ & $\mathrm{P}_{\mathrm{t}}, \mathrm{lbm} / \mathrm{in}^{2}$ & $\mathrm{~T}_{\text {ideal }},{ }^{\circ} \mathrm{R}$ & $\mathrm{V}_{\text {ideal }}, \mathrm{in} / \mathrm{s}$ & $\mathrm{Flow}, \mathrm{lbm} / \mathrm{s}$ & $\mathrm{T}_{\mathrm{aw}},{ }^{\circ} \mathrm{F}$ & Comments \\
\hline 1 & 1.46 & 540 & 80 & 0.756 & 21.46 & 484.7 & 9789.3 & 1.856 & 71.3 & $\mathrm{BPR} 8, \mathrm{CB}$ \\
2 & 1.62 & 540 & 80 & 0.860 & 23.81 & 470.5 & 10972.6 & 2.143 & 69.0 & BPR 8, TO \\
3 & 1.75 & 540 & 80 & 0.931 & 25.73 & 460.2 & 11754.5 & 2.346 & 67.4 & BPR 5, TO \\
\hline
\end{tabular}

A typical test in the SAJF consisted of the following. A run without flow was performed first in each case to serve as a baseline. Then, flow was established at a constant total temperature and plenum pressure was controlled to successively achieve each of the NPR settings in Table 2 in either ascending or descending order. Laser, strain, and thermocouple data were collected essentially throughout the test, i.e., the entire flow profile. Open- and/or closed-loop chevron runs were conducted with constant NPR at each of the settings in a test. Performance data associated with each of the chevron runs included the laser, strain, thermocouple, and IR thermography data collected throughout the run and PMI data (50-frame averages) collected at specific conditions of interest within the run. Initial tests were focused on establishing repeatability and investigating essential parameters such as the current (power) required to bring the top actuator assembly centerline average temperature to nominally $250^{\circ} \mathrm{F}\left(121.1^{\circ} \mathrm{C}\right)$, as indicated by IR measurements. It is noted that the setpoint temperatures were also well represented by TC3 measurements. The nominal current (power) required to achieve the $250^{\circ} \mathrm{F}\left(121.1^{\circ} \mathrm{C}\right)$ setpoint at NPRs of $1.46,1.62$, and 1.75 was $7.35(42.5), 7.75(47.2), 8.125$ (51.9) Amps (Watts), respectively.

Representative results from open-loop runs without flow and with flow at the three NPRs are shown in Figure 17 and Figure 18, which show near-tip deflection and thermocouple measurements versus time, respectively. Recall that the chevron was permanently deformed after the bench top testing. This deformed state was considered to be the new reference or zero-deflection state for the SAJF tests described here. The chevron was nominally in the new reference state at the start of the test, and after the initial tests, as indicated by the near-tip deflection of -0.002 inches $(-0.005 \mathrm{~cm})$ at time $\mathrm{t}=0$ in Figure 17. The first 12 minutes of data correspond to the no flow condition and show a chevron near-tip relative immersion, heated minus unheated near-tip position, of 0.057 inches $(0.031 \mathrm{~cm})$ as the Nitinol was heated by 2.25 Amps of current. The slow thermal response of the chevron is evident in this no-flow case, where heating and cooling occurred over several minutes. Note that the chevron temperature, i.e., TC3, was driven over the $250^{\circ} \mathrm{F}$ $\left(121.1^{\circ} \mathrm{C}\right)$ target, which accounts for the enhanced deflection performance for this open-loop run.

Flow was initiated at $\sim \mathrm{t}=12$ minutes and the NPR setting of 1.75 was achieved at $\sim \mathrm{t}=20$ minutes. The negative deflection values indicate that the chevron was deflected away from the flow and the new reference shape and toward the original 
un-deflected shape as the NPR increased. The flow-induced relative deflection is 0.015 inches $(0.038 \mathrm{~cm})$. The openloop controlled performance shows rapid heating and relative immersion of 0.040 inches $(0.102 \mathrm{~cm})$ followed by rapid cooling and retraction. The NPR was decreased to 1.62 from $\sim \mathrm{t}=27$ to $\mathrm{t}=30$ minutes and the reduced pressure allowed the chevron to recover 0.002 inches $(0.005 \mathrm{~cm})$ of the permanent deflection. The open loop run at the 1.62 NPR produced a relative immersion of 0.043 inches $(0.109 \mathrm{~cm})$. The pressure was reduced again at $\sim \mathrm{t}=36$ minutes and achieved the 1.46 NPR at $\sim \mathbf{t}=39$ minutes. The chevron recovered an additional 0.003 inches $(0.008 \mathrm{~cm})$ of the permanent deflection at the reduced pressure and an open-loop run at $\sim \mathrm{t}=40$ minutes produced a relative immersion of 0.046 inches $(0.117 \mathrm{~cm})$. The chevron temperature (TC3) closely matched the $250^{\circ} \mathrm{F}\left(121.1^{\circ} \mathrm{C}\right)$ target at the maximum immersion condition for all of the open-loop runs with flow. The thermal and deflection response of the chevron in all of the runs with flow was quite rapid because of the ability to readily dissipate the heat.

The actuation relative immersion and flow-induced relative deflection were repeatable within tests and between tests to approximately \pm 0.001 inches $( \pm 0.003 \mathrm{~cm})$. Consequently, the absolute deflection, deflection relative to the permanently deflected reference state, due to actuation and/or flow was also very repeatable with similar accuracy. The average relative near-tip immersion due to actuation at the $250^{\circ} \mathrm{F}\left(121.1^{\circ} \mathrm{C}\right)$ setpoint were 0.047 inches $(0.119 \mathrm{~cm})$ without flow and $0.046,0.043$, and 0.040 inches $(0.117,0.109$, and $0.102 \mathrm{~cm})$ with flow at NPRs of $1.46,1.62$, and 1.75 , respectively. The average relative near-tip deflections due to flow without actuation were $0.009,0.013$, and 0.015 inches $(0.023$, 0.030 , and $0.038 \mathrm{~cm}$ ) for the three NPRs, respectively. Thus, the immersion control (actuation authority) is relatively insensitive to the flow loading and the flow assisted in returning the chevron toward the original un-deflected shape in the un-actuated condition, nominally achieving the original un-deflected shape at the highest NPR of 1.75. The most notable variation in the testing was the chevron near-tip position at the beginning of each test, which depended on the conditions at the end of the previous test, e.g., flow versus no flow. This effect could always be rectified by subjecting the chevron to a thermal cycle without flow to regain the permanently deflected reference configuration. Although the thermocouple results showed significant heating at all locations in the runs without flow, consistent with the bench top testing, slight cooling was observed at the outboard locations for the runs with flow because $T_{\text {aw }}$ is slightly less than room temperature. Thus, strain measurements at locations away from the actuators and in the presence of near-room temperature flow will exhibit negligible temperature effect.

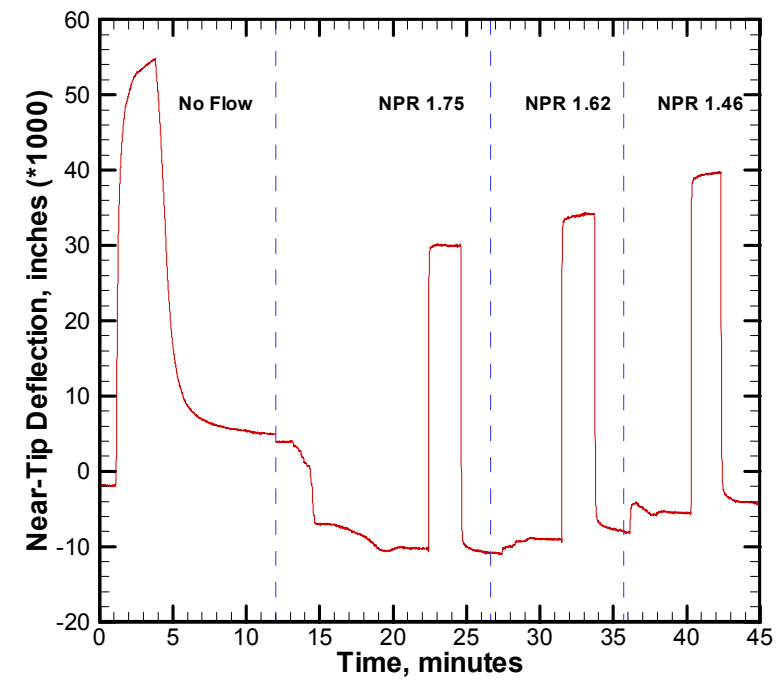

Figure 17: Near-tip deflection in open-loop runs without flow and at the three NPR settings.

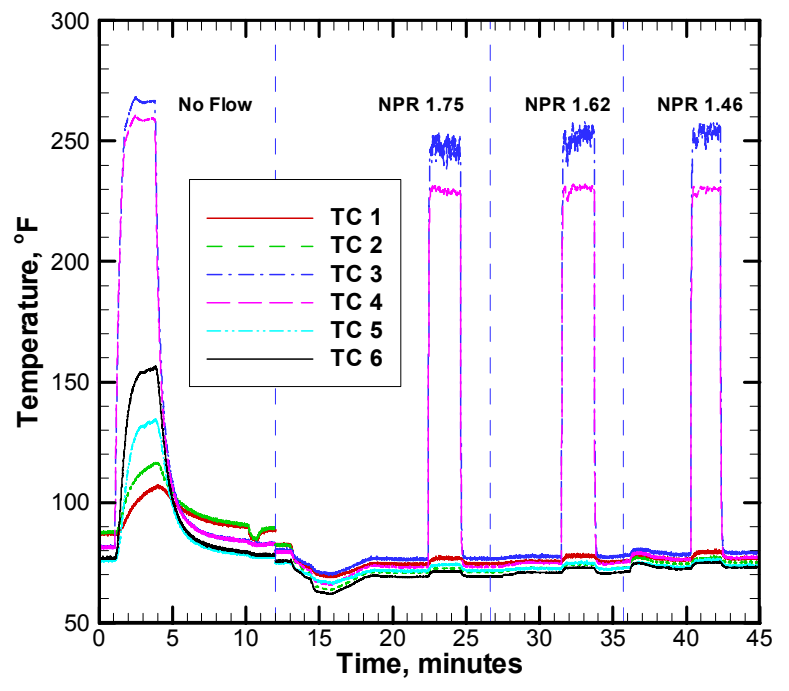

Figure 18: Temperatures in open-loop runs without flow and at the three NPR settings.

Representative closed-loop results for a run with flow at a NPR of 1.75 are shown in Figure 19 and Figure 20. The output of the laser displacement transducer was used for feedback. The closed-loop run was started after an open-loop run at the same NPR, where the final near-tip deflection was -0.012 inches $(-0.030 \mathrm{~cm})$. Near-tip positions of 0.015 , 0.023 , and 0.000 inches $(0.038,0.058,0.000 \mathrm{~cm})$ were commanded as shown with the corresponding chevron response in Figure 19. It can be seen that excellent control performance was achieved for increasing (heating) and decreasing (cooling) the immersion. The filled circles at the beginning and end of the setpoint distribution indicate the onset and termination of closed-loop control. The current commanded by the controller to achieve the prescribed near-tip position 
distribution is shown in Figure 20. It can be seen that the rapid and over-damped deflection response was easily achieved with a maximum current input of approximately 6.8 Amps.

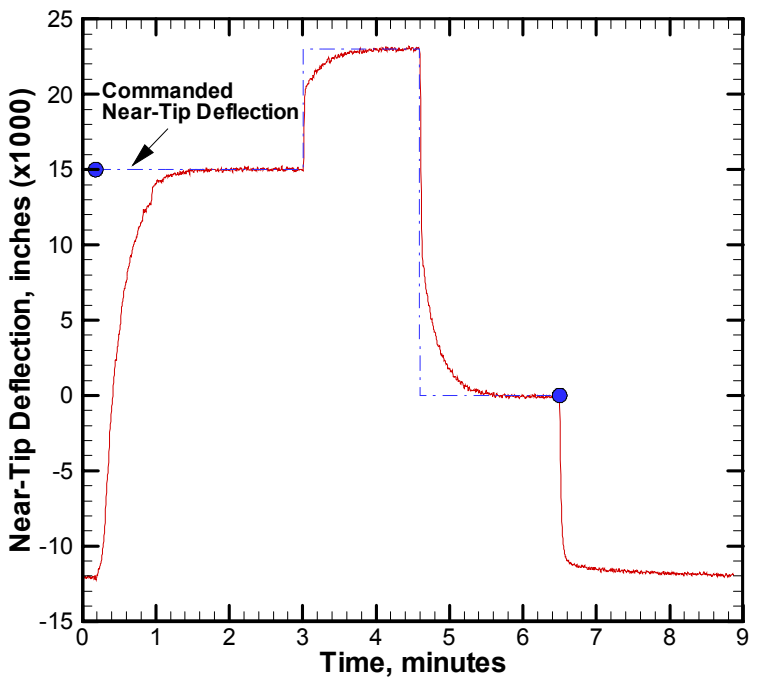

Figure 19: Commanded and measured near-tip deflection with flow at a NPR of 1.75 .

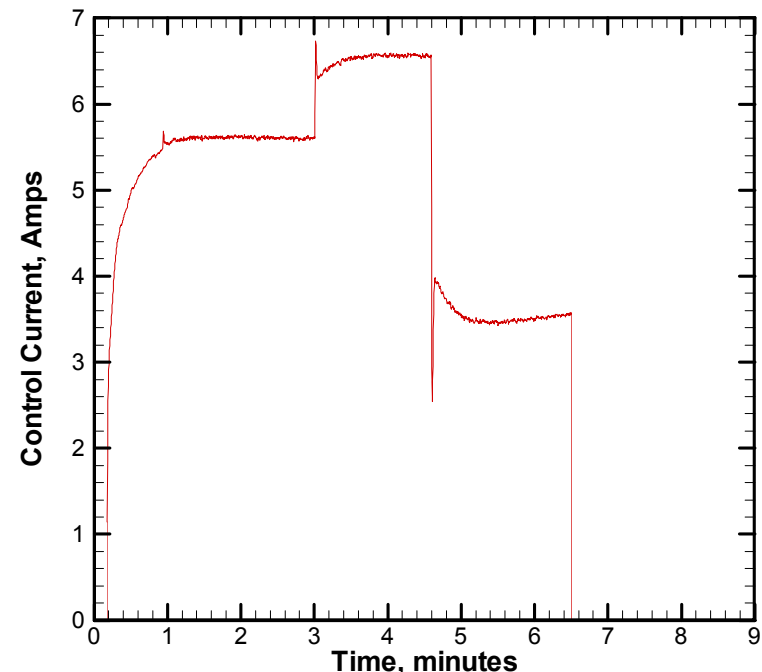

Figure 20: Control current profile required to achieve the closed-loop response with flow at a NPR of 1.75 .

\section{SUMMARY AND CONCLUSIONS}

A novel approach for active jet nozzle chevrons has been developed based upon shape memory alloy hybrid composite (SMAHC) technology. The concept involves embedding prestrained SMA actuators on one side of the chevron midsurface in order to generate a thermal moment and deflect the structure out-of-plane when heated. The force developed in the host structure during deflection is used for returning the structure to the retracted position. The motivation for this work is to develop active chevrons at model scale with provisions for electrical activation and active control to enable laboratory-based parametric studies, although the approach is thought to be applicable for autonomous environmental adaptation. The objectives of this study were to fabricate SMAHC chevrons at model scale, develop numerical models, and correlate predicted and measured performance to achieve a validated design tool and a prototype chevron design.

A chevron design incorporating five layers of glass-epoxy and two Nitinol actuator assemblies, consisting of two Nitinol strands each, aligned with and near the chevron centerline was developed from testing and numerical results. Requirements of minimum overall thickness and electrical activation of the Nitinol actuators were accommodated by fabricating actuator assemblies from two strands of Nitinol ribbon using spot welds at a specific location. Subsequent placement of the actuator assemblies in the laminate with the welds near the chevron tip and glass-epoxy separating the Nitinol layers enabled electrical access to the actuators at the root of the chevron and electrical continuity within the chevron through the welds. A vacuum hot press consolidation approach was used for consolidation of the laminate.

Bench top tests of the chevron were performed with a rigorous and comprehensive measurement system. Thermal cycles were performed between room temperature and $250^{\circ} \mathrm{F}\left(121.1^{\circ} \mathrm{C}\right)$ while measuring the full-field temperatures and deflections. A finite element model was constructed for the chevron geometry and input files were generated for nonlinear static analyses in MSC.Nastran and ABAQUS according to a recently commercialized constitutive model for SMA and SMAHC materials. Excellent agreement between the bench top test results and the numerical predictions was achieved. The performance goal of 0.050 inches $(0.127 \mathrm{~cm})$ of tip deflection was also achieved. Slight permanent deformation of the chevron remained subsequent to the bench top tests.

Tests were also conducted on the chevron in the Small Anechoic Jet Facility (SAJF) at NASA Langley to determine the effects of representative flow conditions on the temperature distribution, power requirements, deflection performance, and controllability. The chevron deflection performance was found to be relatively insensitive to the nozzle pressure ratio (NPR). The flow did, however, assist in returning the chevron to the original un-deflected shape to an increasing 
degree with increasing NPR, nominally achieving full return to the un-deflected shape at the highest NPR. All aspects of the chevron performance were found to be very repeatable. Excellent closed-loop performance of the chevron tip immersion was achieved, based upon tip deflection measurements, and provisions for closed-loop control using strain and temperature measurements only is under development. Extension of this technology to chevrons with the cylindrical radius of curvature and to development of an entire active chevron nozzle assembly at model scale is also underway.

\section{ACKNOWLEDGEMENTS}

The authors gratefully acknowledge the following contributors to this work: Sean Britton (NASA LaRC) for his assistance in fabricating the chevron specimens; George Hilton (NASA LaRC) for his help in chevron fabrication, test system development and data collection; Larry Becker and Brian Howerton (Lockheed Martin) for their work in developing the LabVIEW-based thermal controller/data acquisition system; Felecia Berry (NASA LaRC) for her assistance in configuring the PMI system and acquiring data; Mark Roth and Mark Clemons (Modern Machine and Tool Company, Inc.) for strain instrumentation installation and data acquisition assistance; and John Swartzbaugh, Jeff Collins, Jeff Conover, and Clinton Reese for their assistance in configuring and running the SAJF apparatus.

\section{REFERENCES}

1. N. H. Saiyed, K. L. Mikkelsen, and J. E. Bridges, "Acoustics and Thrust of Separate-Flow Exhaust Nozzles with Mixing Devices for High-Bypass-Ratio Engines," $6^{\text {th }}$ AIAA/CEAS Aeroacoustics Conference, AIAA Paper 20001961, Lahaina, HI, 2000.

2. R. H. Thomas, K. W. Kinzie, and S. P. Pao, "Computational Analysis of a Pylon-Chevron Core Nozzle Interaction", $7^{\text {th }}$ AIAA/CEAS Aeroacoustics Conference, AIAA Paper 2001-2185, Maastricht, The Netherlands, 2001.

3. B. Callender, E. Gutmark, and S. Martens, "A Near-Field Investigation of Chevron Nozzle Mechanisms", $9^{\text {th }}$ AIAA/CEAS Aeroacoustics Conference and Exhibit, AIAA Paper 2003-3210, Hilton Head, SC, 2003.

4. S. J. Massey, R. H. Thomas, K. S. Abdol-HAmid, and A. A. Elmiligui, "Computational and Experimental Flow Field Analyses of Separate Flow Chevron Nozzles and Pylon Interaction", 9 $9^{\text {th }}$ AIAA/CEAS Aeroacoustics Conference and Exhibit, AIAA Paper 2003-3212, Hilton Head, SC, 2003.

5. O. Rask, E. Gutmark, and S. Martens, "Acoustic Investigation of a High Bypass Ratio Separate Flow Exhaust System”, 42 ${ }^{\text {nd }}$ AIAA Aerosciences Meeting and Exhibit, AIAA Paper 2004-9, Reno, NV, 2004.

6. L. D. Koch, J. Bridges, and A. Khavaran, "Mean Flow and Noise Prediction for a Separate Flow Jet with Chevron Mixers", 42 ${ }^{\text {nd }}$ AIAA Aerosciences Meeting and Exhibit, AIAA Paper 2004-189, Reno, NV, 2004.

7. B. Callender, E. Gutmark, and S. Martens, "A PIV Flow Field Investigation of Chevron Nozzle Mechanism", $42^{\text {nd }}$ AIAA Aerosciences Meeting and Exhibit, AIAA Paper 2004-191, Reno, NV, 2004.

8. J. Bridges and C. A. Brown, "Parametric Testing on Chevrons on Single Flow Hot Jets", $10^{\text {th }}$ AIAA/CEAS Aeroacoustics Conference, AIAA Paper 2004-2824, 2004.

9. M. J. Doty, B. S. Henderson, and K. W. Kinzie, "Turbulent Flow Field Measurements of Separate Flow Round and Chevron Nozzles with Pylon Interaction Using Particle Image Velocimetry", $10^{\text {th }}$ AIAA/CEAS Aeroacoustics Conference, AIAA Paper 2004-2826, 2004.

10. B. Callender, E. Gutmark, and S. Martens, "Far-Field Acoustic Investigation into Chevron Nozzle Mechanisms and Trends", AIAA Journal, 43(1) 87-95, 2005.

11. V. G. Mengle, "Relative Clocking of Enhanced Mixing Devices for Jet Noise Benefit," $43^{\text {rd }}$ AIAA Aerospace Sciences Meeting and Exhibit, AIAA Paper 2005-996, Reno, NV, 2005.

12. V. G. Mengle, "Jet Noise Characteristics of Chevrons in Internally Mixed Nozzles," 11th AIAA/CEAS Aeroacoustics Conference, AIAA Paper 2005-2934, Monterey, CA, 2005.

13. F. T. Calkins and G. W. Butler, "Subsonic Jet Noise Reduction Variable Geometry Chevron", $42^{\text {nd }}$ AIAA Aerospace Sciences Meeting and Exhibit, AIAA Paper 2004-0190, Reno, NV, 2004.

14. J. H. Mabe, R. T. Ruggeri, G. W. Butler, and S. Sellmeyer, "Morphing Chevrons for Take Off and Cruise Noise Reduction," The 2004 International Symposium on Active Control of Sound and Vibration (ACTIVE 2004), INCE/USA, Williamsburg, VA, 2004.

15. J. H. Mabe, R. H. Cabell, and G. W. Butler, "Design and Control of a Morphing Chevron for Takeoff and Cruise Noise Reduction," $11^{\text {th }}$ AIAA/CEAS Aeroacoustics Conference, AIAA Paper 2005-2889, Monterey, CA, 2005.

16. T. L. Turner, "Thermomechanical Response of Shape Memory Alloy Hybrid Composites," NASA/TM-2001-210656, 2001. 
17. T. L. Turner, C. L. Lach, and R. J. Cano, "Fabrication and Characterization of SMA Hybrid Composites," in Smart Structures and Materials 2001: Active Materials: Behavior and Mechanics, C. S. Lynch (Editor) Proceedings of SPIE Vol. 4333, 343-354 (2001).

18. T. L. Turner, "Structural Acoustic Response of a Shape Memory Alloy Hybrid Composite Panel (Lessons Learned)," in Smart Structures and Materials 2002: Smart Structures and Integrated Systems, L. P. Davis (Editor), Proceedings of SPIE Vol. 4701, 592-603 (2002).

19. H. A. Bruck, C. L. Moore, and T. L. Valentine, "Repeatable Bending Actuation in Polyurethanes Using Opposing Embedded One-Way Shape Memory Alloy Wires," Smart Mater. Struct. 11(4) 509-518, 2002.

20. C. Kim, B.-S. Park, and N.-S. Goo, "Shape Changes by Coupled Bending and Twisting of Shape-Memory-AlloyEmbedded Composite Beams," Smart Mater. Struct. 11(4) 519-526, 2002

21. R. Chandra, "Active Shape Control of Composite Blades Using Shape Memory Actuation," Smart Mater. Struct. 10(5) 1018-1024, 2001.

22. A. Baz, T. Chen, and J. Ro, "Shape Control of NITINOL-Reinforced Composite Beams," Composites: PartB, 31(8) 631-642, 2000.

23. Turner, T. L.; Buehrle, R. D.; Cano, R. J.; and Fleming, G. A.: "Design, Fabrication and Testing of SMA Enabled Adaptive Chevrons for Jet Noise Reduction," in Smart Structures and Materials 2004: Smart Structures and Integrated Systems, A. B. Flatau (Editor), Proceedings of SPIE Vol. 5390 (SPIE, Bellingham, WA, 2004$) 297-308$.

24. Turner, T. L.; Buehrle, R. D.; Cano, R. J.; and Fleming, G. A.: "Modeling, Fabrication, and Testing of a SMA Hybrid Composite Jet Engine Chevron Concept," The 2004 International Symposium on Active Control of Sound and Vibration (ACTIVE 04), INCE/USA, Williamsburg, VA, 20-22 September 2004.

25. Turner, T. L.; Buehrle, R. D.; Cano, R. J.; and Fleming, G. A.: "Modeling, Fabrication, and Testing of a SMA Hybrid Composite Jet Engine Chevron Concept," in print J. of Intelligent Matl. Systems and Structures, Feb. 2005.

26. Turner, T. L. and Patel, H. D.: "Analysis of SMA Hybrid Composite Structures Using Commercial Codes," in Smart Structures and Materials 2004: Modeling, Signal Processing, and Control, R. C. Smith (Editor), Proceedings of SPIE Vol. 5383 (SPIE, Bellingham, WA, 2004) 82-93.

27. Turner, T. L. and Patel, H. D.: "Input Files and Procedures for Analysis of SMA Hybrid Composite Beams in MSC.Nastran and ABAQUS," NASA/TM-2005-213517, January 2005.

28. Turner, T. L. and Patel, H. D.: "Analysis of SMA Hybrid Composite Structures in MSC.Nastran and ABAQUS," submitted to J. of Intelligent Matl. Systems and Structures, January 2006.

29. R. H. Cabell, N. H. Schiller, J. H. Mabe, R. T. Ruggeri, and G. W. Butler, "Feedback Control of a Morphing Chevron for Takeoff and Cruise Noise Reduction," The 2004 International Symposium on Active Control of Sound and Vibration (ACTIVE 04), INCE/USA, Williamsburg, VA, 20-22 September 2004. 